Dicle University Journal of Engineering (DUJE)

web: http://dergipark.gov.tr/dumf

Araştırma Makalesi / Research Article

\title{
Yığma duvarların mikro modellemesinde harcın çekme dayanımı ve kayma gerilmesi iletim katsayısının etkisi
}

\section{Effect of tensile strength and shear transfer coefficient of the mortar in micro modeling of masonry walls}

\author{
Muhammet Karaton ${ }^{1 *}$, Kağan Çanakçı \\ ${ }^{1}$ Fırat Üniversitesi, İnşaat Mühendisliği Bölümü, Elazı̆̆, mkaraton@ firat.edu.tr, https://orcid.org/0000-0002-1498-4659 \\ ${ }^{2}$ Frrat Üniversitesi, İnşaat Mühendisliği Bölümü, Elazığ, canakcikagan@ gmail.com, https://orcid.org/0000-0002-8701-2762
}

\begin{tabular}{|c|c|}
\hline MAKALE BİLGILERİ & ÖZET \\
\hline & \multirow{5}{*}{$\begin{array}{l}\text { Bu çalışmada, yığma duvarların mikro model ile analizinde } 3 \text { boyutlu sabit doğrultulu yayılı } \\
\text { çatlak modelinin etkinliği incelenmiştir. Duvarın harç ve tuğla kısımlarının lineer olmayan } \\
\text { davranışını hesaplamak için William ve Warnke modelinin özel hali olan üç değişkenli beton } \\
\text { modeli kullanılmıştır. Nümerik analizler için Ansys sonlu eleman programı içerisinde } \\
\text { bulunan Solid65 beton elemanı seçilmiştir. Nümerik sonuçların karşışlaştılılması amacıyla, } \\
\text { JD4, JD6 ve JD7 Eindhoven duvarlarının deney sonuçlarından elde edilen taban kesme } \\
\text { kuvveti-tepe yer değiştirme eğrisi ile oluşan çatlak bölgeleri kullanılmışı.ı. Harcın çekme } \\
\text { dayanımının ve bu bölgenin sonlu eleman modelinde tanımlanan kayma gerilmesi iletim } \\
\text { katsayısının nümerik çözümler üzerine olan etkisi incelenmiştir. Yığma yapıların mikro } \\
\text { seviye statik itme analizlerinde kullanılması amacıyla harcın çekme dayanımı için bir katsayı } \\
\text { ve kayma gerilmesi iletim katsayıları için bazı değerler önerilmiştir. }\end{array}$} \\
\hline Geliş: 9 Aralık 2019 & \\
\hline $\begin{array}{l}\text { Düzeltme: } 7 \text { Ocak } 2021 \\
\text { Kabul: } 10 \text { Ocak } 2021\end{array}$ & \\
\hline Anahtar kelimeler: & \\
\hline $\begin{array}{l}\text { Eindhoven duvarları, mikro } \\
\text { modelleme, yayilı çatlak modeli, } \\
\text { harcın basınç dayanımı ve kayma } \\
\text { gerilmesi iletim katsayısı. }\end{array}$ & \\
\hline
\end{tabular}

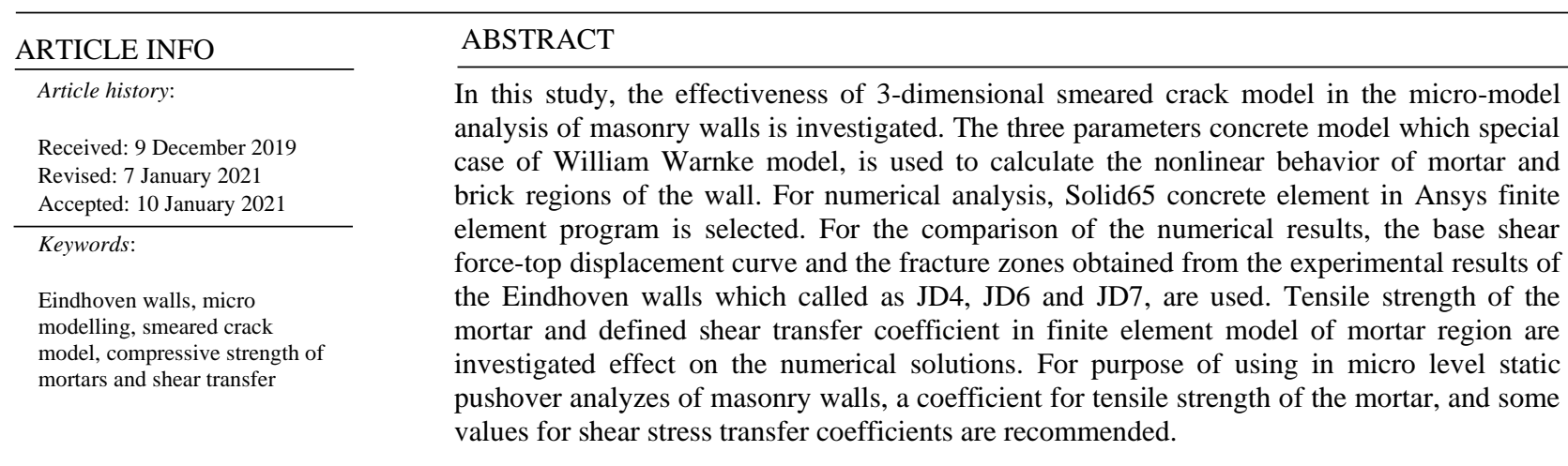




\section{Giriș}

Yığma duvarlar, bina inşaatlarında belirli alanların ayrılmasında tercih edilen önemli yapı elemanlarıdır. Yı̆̆ma duvarlar tuğla/taş ve harçtan meydana geldiği için kompozit bir malzeme davranışına sahiptir. $\mathrm{Bu}$ duvarların nümerik olarak modellenmesi farklı malzeme etkileşim ve davranışlarından dolayı karmaşık işlemler gerektirmektedir. $\mathrm{Bu}$ nedenle söz konusu yapıların nümerik modellemesi üzerinde otuz yılı aşan bir süreden beri araştırmalar devam etmektedir. Yığma duvarların nümerik modellenmesi konusunda mikro, basitleştirilmiş mikro ve makro modelleme teknikleri geliştirilmiştir [1]. Mikro ölçekli analizlerde yığma birimler ayrı ayrı modellenmektedir. Basitleştirilmiş mikro modelde ise tuğla/taş ile harç arasında yer alan ara yüzey bölgesi sonlu elemanlarla, diğer kısımlar ise rijit veya şekil değiştirebilen ayrık elemanlarla modellenmektedir. Makro modelleme tekniğinde ise tuğla/taş ve harç eşdeğer bir malzemeye dönüştürülmektedir [1].

Yığma duvarların mikro ölçekli analizlerinde birçok araştırma yapılmış olup bunlar içerisinde, Adam ve ark. [2], sonlu elemanlar yöntemi ile bir mikro mekanik model geliştirmişlerdir. Sonlu eleman modelinde harç ve tuğla, katı eleman olarak bu iki ortamın ara yüzü ise ara yüzey elemanlar kullanılarak modellenmiştir. Katı elemanların doğrusal olmayan davranışları için sabit doğrultulu yayılı çatlak modelini kullanmışlardır. Doğrusal olmayan nümerik analiz sonuçları ile deney sonuçları yük-yer değiştirme ve eğilme momenti-dönme tepkileri açısından karşılaştırılmıştır. Mohyeddin ve ark. [3], üç boyutlu ayrık sonlu elemanlar kullanarak yı̆̆ma duvar ile doldurulmuş betonarme çerçevelerin analizlerini elde etmişlerdir. Çözümlerinde, Ansys sonlu elemanlar programını kullanmışlardır. Harç ve tuğla bölgelerinin doğrusal olmayan davranışları için sabit doğrultulu yayılı çatlak modelini kullanmışlardır. $\mathrm{Bu}$ modelin etkinliğini incelemek amaciyla literatürde yer alan deneysel verilerden yararlanmışlardır. Modelin düzlem içi ve düzlem dışı yükleme durumlarında, dolgu çerçeve üzerindeki etkisini doğru bir şekilde yansıttığını göstermişlerdir. Petracca ve ark. [4] yığma duvarların analizi için yeni bir hasar mekaniği tabanlı sürekli ortama ait mikro model sunmuşlardır. $\mathrm{Bu}$ modeli literatürde yer alan ayrık mikro modelleme yöntemleriyle karşılaştırmışlardır. Zucchini ve Lourenço [5], yığma duvarların, doğrusal olmayan analizi için bir mikro mekanik model geliştirmişlerdir ve Vermeltfoort ile Raijmakers [6]' in yı̆̆ma duvarlar için yaptıkları deney sonuçlarını kullanarak modelin doğrulamasını yapmışlardır. Chaimoon ve Attard [7], donatısız yığma duvarların, kesme ve basınç yüklemeleri altındaki doğrusal olmayan davranışını analiz etmek için bir model sundular ve bu modelin doğrulamasını yapmak amaciyla Vermeltfoort ve ark. [8]' nın yığma duvarlar için yaptıkları deney sonuçlarıyla karşılaştırmışlardır.

Yukarıda verilen literatür incelemesinden yığma duvarların nümerik analizlerinde kırılma ve hasar mekaniği teorilerinden faydalanıldığ görülmektedir. Yığma duvarların mikro ölçekli analizlerinde sabit doğrultulu yayılı çatlak modeli en yaygın olarak kullanılan modellerden biridir. $\mathrm{Bu}$ sebepten yığma yapıların mikro ölçekli analizlerinde söz konusu metodun nümerik çözümler üzerindeki etkinliğinin incelenmesi önem arz etmektedir. Birçok araştırmacı Eindhoven duvarı deney sonuçlarından elde edilen kuvvet-yer değiştirme eğrileri ve çatlak geometrisini elde etmek için makro ve mikro modelleme tekniklerini kullanarak incelemeler yapmışlardır. [9] $\mathrm{Bu}$ nedenle nümerik sonuçları karşılaştırmak amacıyla Eindhoven duvarı deney sonuçlarından elde edilen deney verileri kullanılmıştır.

Bu çalışmada, yığma duvarların mikro model ile analizinde JD4, JD6 ve JD7 Eindhoven duvarlarının [6] 3 boyutlu sabit doğrultulu yayılı çatlak yaklaşımı ile doğrusal olmayan statik itme analizleri yapılmıştır. Duvarın harç ve tuğla kısımlarının lineer olmayan davranışını hesaplamak için William ve Warnke modelinin özel bir hali olan üç değişkenli beton modeli kullanılmıştır. Nümerik analizler için Ansys sonlu eleman programı içerisinde bulunan Solid65 beton elemanı seçilmiştir. $\mathrm{Bu}$ model yığma duvarların nümerik modellenmesinde yaygın olarak kullanılmıştır [1-3]. Tüm bu 
sebeplerden bu çalışmada mikro seviye modelde kullanılan harcın çekme dayanımının ve kayma gerilmesi iletim katsayısının nümerik çözümler üzerindeki etkisi incelenmiștir. Eindhoven duvarlarının deney sonuçlarından elde edilen taban kesme kuvveti-tepe yer değiştirme eğrisi ile oluşan çatlak bölgeleri nümerik sonuçlarla karşılaştırılarak yöntemin etkinliği incelenmiştir.

\section{William-Warkne modeli}

$\mathrm{Bu}$ çalışmada, William ve Warnke [10], modelinin özel hali olan üç değişkenli beton modeli kullanılmıştır. Üç değişkenli model William tarafından geliştirilmiş olup, düşük basınç altında çekmeye maruz kesitlerdeki beton için göçme yüzeyini tanımlamaktadır. Zeinkiewicz ve Taylor [11], beton gibi gevrek özelliğe sahip malzemeler için bu malzeme modelinin kullanılabileceğini ortaya koymuşlardır.

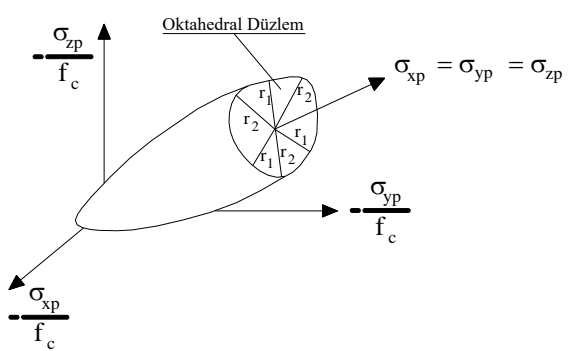

a)

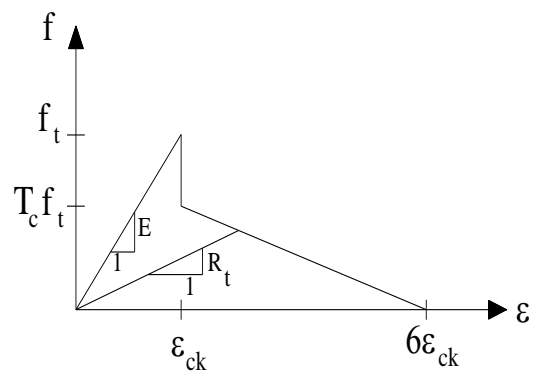

b)

Şekil 1. Üç parametreli model için a) göçme yüzeyi ve b) tek eksenli gerilme-şekil değiştirme bağıntısı [9].

William-Warnke' nin beton göçme yüzeyi modeli yığma yapıların geniş çapta modellemesinde etkin bir şekilde kullanılmıştır [12]. Bu model, Şekil 1.a' da görüldüğü gibi kesiti konveks olan bir koniye yakın görünüme sahiptir. Konveks kesit, simetrik ve düzgün yapıdadır. Burada, $\sigma_{\text {хр }}, \sigma_{\text {yp }}$ ve $\sigma_{\text {zp }}$ birbirlerine dik asal gerilmeleri, $f_{c}$ ise malzemenin tek eksenli basınç dayanımını belirtmektedir. Aynı zamanda, von Mises veya Drucker-Prager yaklaşımları bu modelin özel bir durumu olarak belirlenebilir [13]. Bu modelde, göçme yüzeyi içerisinde kalan gerilme değerleri elde edildiğinde malzeme doğrusal elastik davranış göstermektedir. Göçme yüzeyinin dışına çıkılan gerilme değerleri elde edildiğinde ise malzemede çatlama ve ezilmelerin ortaya çıkacağı ifade edilmektedir. Malzemede ortaya çıkan çatlaklar gerilme yumuşaması (stress softening) olarak dikkate alınmaktadır (Şekil 1.b).

\section{JD4, JD6 ve JD7 Eindhoven yığma duvarlarının mikro model analizi}

$\mathrm{Bu}$ çalışmada, JD4, JD6 ve JD7 Eindhoven yığma duvarlarının mikro ölçekli modeli kullanılarak doğrusal olmayan statik itme analizleri yapılmıştır. Bu duvarların boyutları $990 \times 1000 \times 100 \mathrm{~mm}$ olup $210 \times 52 \times 100 \mathrm{~mm}$ ölçülerinde sahip tuğlalar ile harç kalınlığı 10 $\mathrm{mm}$ olacak șekilde 16 sira tuğla-harç kullanılarak inşa edilmiştir. Modelin en üst ve en altında 2 sıra çelik kiriş yer almaktadır. Deneysel çalışmada, ön yükleme olarak üst kirişe düşey bir tekil yük uygulanmış olup sonraki yükleme adımında ise aynı kirişe yatay yer değiştirme yükü uygulanarak duvarın kuvvet-yer değiştirme grafiği ile çatlak bölgeleri elde edilmiştir. Söz konusu bu ön yükleme durumu 30, 120 ve 210 $\mathrm{kN}$ olarak uygulanmış ve Eindhoven yı̆̆ma duvarları sirasiyla JD4, JD6 ve JD7 olarak adlandırılmıștır.[6]. Bu duvarlar arasındaki tek fark toplam düşey yüktür.

$\mathrm{Bu}$ modelde harç ve tuğla için ayrı ayrı malzeme özellikleri tanımlanmış olup malzemeler arası bağlantının rijit olduğu kabul edilmiş ve herhangi bir ara yüzey elemanı kullanılmamıştır. Çözümler için Ansys sonlu eleman programı kullanılmıştır. Sayısal modelde 33600 adet düğüm noktası ve 21978 adet üç boyutlu katı sonlu eleman kullanılmıştır (Şekil 2). Duvarın tabanındaki çelik kirişlerin alt yüzeyi yatay ve düşey doğrultularda tutulu, üstteki çelik kirişin üst yüzeyi ise sadece düşey doğrultuda tutulu 
olacak şekilde sınır şartları uygulanmıştır (Şekil 3).

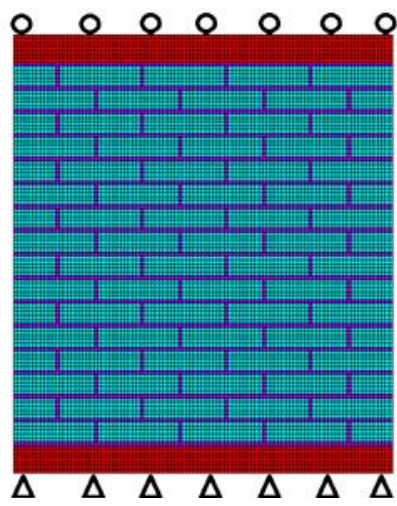

Şekil 2. Eindhoven duvarlarının sonlu elemanlar modeli ve sinır şartlart.

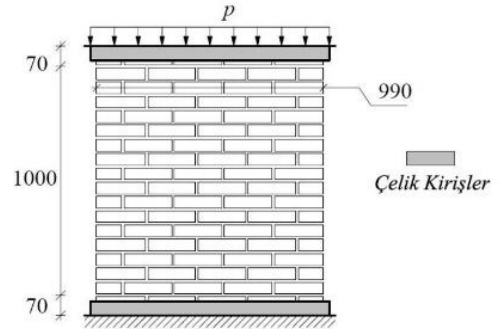

a)

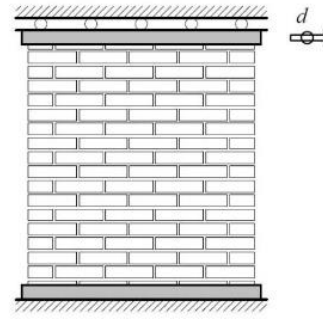

b)
Şekil 3. Eindhoven duvarlarının düşey ve yatay yükleme durumlarl.

$\mathrm{Bu}$ çalışmada, Eindhoven yığma duvarlarının mikro modelleme ile doğrusal olmayan statik itme analizlerinde; harcın çekme dayanımının ve kayma gerilmesi iletim katsayısı $\beta_{t}$ 'nin çözümler üzerine olan etkisi incelenmiştir. Tuğla ve harç malzemelerinin elastik ve elastik olmayan malzeme özellikleri Hemant ve ark. [14]' nın önerdiği eşitlikler yardımıyla belirlenmiştir. $\mathrm{Bu}$ araştırmada tuğla malzemesinin elastisite modülü,

$$
E_{b}=300 f_{b, c} \quad(\mathrm{MPa})
$$

eşitliği ile hesaplanmaktadır. Burada $f_{b, c}$ tuğlanın tek eksenli basınç dayanımını göstermektedir. Tuğla malzemesinin tek eksenli çekme dayanımı $f_{b, t}$ ise,

$$
f_{b, t}=f_{b, c} / 25 \quad(\mathrm{MPa})
$$

denklemi ile hesaplanmaktadır. Harç malzemesinin elastisite modülü ise,

$$
E_{m}=200 f_{m, c} \quad(\mathrm{MPa})
$$

\section{Harcın çekme dayanımının çözümler üzerindeki etkisi}

$\mathrm{Bu}$ bölümde JD4, JD6 ve JD7 Eindhoven duvarlarında kullanılan harcın çekme dayanımının, yığma duvarın nümerik analizleri üzerindeki etkileri incelenmiştir. JD4, JD6 ve JD7 Eindhoven duvarları için harcın tek eksenli basınç dayanımı $10 \mathrm{MPa}$ olarak seçilmiş olup [14] harcın elastisite modülü değerleri (3) denklemi yardımıyla hesaplanmıştır. Harcın tek eksenli çekme dayanım $\left(f_{m, t}\right)$ değerleri ise sirasiyla $1 / 25,1 / 20,1 / 15,1 / 10$ ve $1 / 5$ katsayıları kullanılarak hesaplanmış olup Tablo 1' de verilmiştir [14]. Tablo 2' de ise söz konusu duvarların tuğla malzemesine ait malzeme özellikleri görülmektedir. Kayma gerilmesi iletim katsayıları ise her iki malzeme de ayn değerlere sahip olduğu kabul edilmiş olup çatlağın açık ve kapalı durumları için sırasıyla 0.05 ve 0.90 olarak dikkate alınmıştır.

Tablo 1. JD4, JD6, JD7 Eindhoven duvarlart harç malzeme özellikleri.

\begin{tabular}{cccccc}
\hline & $M 1$ & $M 2$ & $M 3$ & $M 4$ & $M 5$ \\
\hline$E_{m}$ & 2000 & 2000 & 2000 & 2000 & 2000 \\
$f_{m, c}$ & 10.00 & 10.00 & 10.00 & 10.00 & 10.00 \\
$f_{m, t}$ & 0.40 & 0.50 & 0.67 & 1.00 & 2.00 \\
\hline
\end{tabular}

Tablo 2. JD4, JD6, JD7 Eindhoven duvarlarl tuğla malzeme özellikleri.

\begin{tabular}{cccc}
\hline & $J D 4$ & $J D 6$ & $J D 7$ \\
\hline$E_{b}$ & 3750 & 9000 & 16500 \\
$f_{b, c}$ & 12.50 & 30.00 & 55.00 \\
$f_{b, t}$ & 0.50 & 1.20 & 2.20 \\
\hline
\end{tabular}

JD4 duvarının deney sonuçlarından maksimum taban kesme kuvveti $50.30 \mathrm{kN}$ olarak belirlenmiştir. Nümerik analizlerden hesaplanan taban kesme kuvveti değerleri ise JD4-M1, JD4- 
M2, JD4-M3, JD4-M4 ve JD4-M5 için sırasıyla $50.50,50.21,43.41,52.34$ ve $59.11 \mathrm{kN}$ olarak elde edilmiştir (Şekil 4). Hesaplanan maksimum taban kesme kuvveti değerleri, deney sonuçlarıyla karşılaştırıldığında; JD4-M1, JD4M2, JD4-M3, JD4-M4 ve JD4-M5 için sirasıyla $\% 0.45, \% 0.13, \% 13.65, \% 4.11$ ve $\% 17.5$ oranlarında farkların oluştuğu belirlenmiştir. $\mathrm{Bu}$ değerler dikkate alındığında en az farkın JD4M2 için hesaplandiğı görülmektedir.

JD4 duvarının deney sonuçlarından maksimum yükün oluştuğu andaki duvarın tepe yer değiştirme değeri (eşik yer değiştirme) $1.74 \mathrm{~mm}$ olarak belirlenmiştir. Nümerik analizlerde ise bu yer değiştirme değeri, JD4-M1, JD4-M2, JD4M3, JD4-M4 ve JD4-M5 için sirasiyla 1.60, 1.60, 0.96, 1.60 ve $1.76 \mathrm{~mm}$ olarak elde edilmiştir. $\mathrm{Bu}$ yer değiştirme değerleri deney sonucuyla karşılaştırıldığında, JD4-M1, JD4M2, JD4-M3, JD4-M4 ve JD4-M5'in nümerik sonuçları ile deney sonucu arasında sırasıyla $\% 8.05, \% 8.05, \% 44.83, \% 8.05$ ve $\% 1.15$ oranlarında farklar elde edilmiștir. Bu farklar içerisinde en küçük değer JD4-M5 çözümünden hesaplanmıştır. Ancak, taban kesme kuvvetleri arasındaki farklar dikkate alındığında en büyük farkın bu çözüm için elde edildiği görülmektedir. $\mathrm{Bu}$ nedenle en uygun çözümün JD4-M2 için elde edildiği kabul edilmiştir (Tablo 3).

Tablo 3. JD4 duvart için harcın dayanım değeri değişiminin deney ve nümerik sonuçlar arasindaki farklar üzerindeki etkisi.

\begin{tabular}{ccc}
\hline Duvar Adl & $\begin{array}{c}\text { Maks. Taban } \\
\text { Kesme Kuv. } \\
\text { (\% fark) }\end{array}$ & $\begin{array}{c}\text { Eşik yer } \\
\text { değiştirme } \\
\text { (\% fark) }\end{array}$ \\
\hline JD4-M1 & 0.45 & 8.05 \\
JD4-M2 & $\mathbf{0 . 1 3}$ & $\mathbf{8 . 0 5}$ \\
JD4-M3 & 13.65 & 44.83 \\
JD4-M4 & 4.11 & 8.05 \\
JD4-M5 & 17.5 & 1.15 \\
\hline
\end{tabular}

JD4-M1, JD4-M2, JD4-M3, JD4-M4 ve JD4-M5 için tepe yer değiştirme değerlerinin sirasıyla $1.60,1.60,0.96,1.60$ ve $1.76 \mathrm{~mm}$ ' ye ulaştığ 1 anlarda JD4 duvarında oluşan çatlak bölgeleri ve deneyden elde edilen çatlak bölgeleri Şekil 5' de görülmektedir. Tüm çözümlerde çatlak bölgeleri
JD4 duvarının sağ üst köşesinden başlayıp sola doğru ve sol alt köşesinden başlayıp sağa doğru yatay olarak ilerleyen iki bölge şeklinde elde edilmiştir. İlerleyen yükleme adımlarında JD4M2 çözümü hariç sol üst köşeden sağ alt köşeye doğru ilerleyen diyagonel bir çatlak bölgesi daha meydana gelmiştir. JD4-M2 çözümünde ise bu diyagonel çatlak bölgesi sadece duvar orta bölgesinde yer almıştır. Üst ve alt kısımlarda elde edilen çatlak bölgeleri bu çatlak bölgesi etrafinda dönerek ilerleyen bir forma geçiş yapmıştır. Bu durum JD4-M1, JD4-M4 ve JD4M5 çözümlerinde de görülmektedir.

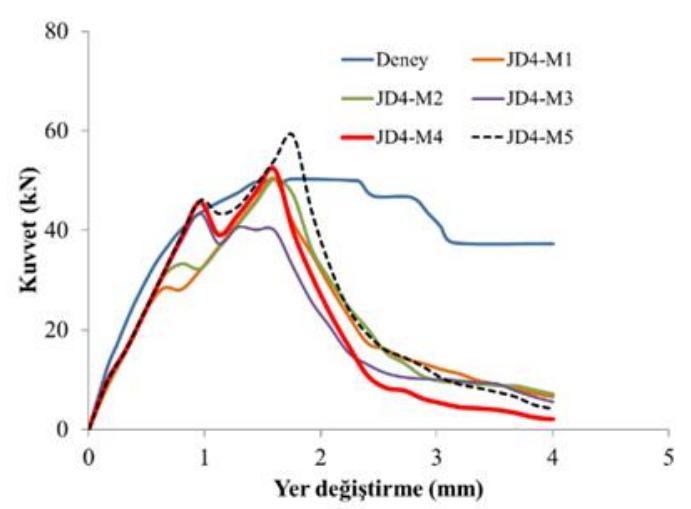

Şekil 4. JD4 Eindhoven duvarinin deney ve nümerik çözümlerden elde edilen kuvvet-yer değiştirme grafikleri.

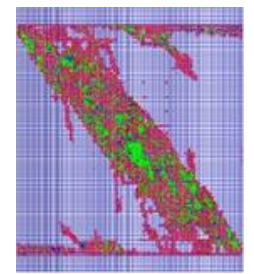

a) JD4-M1

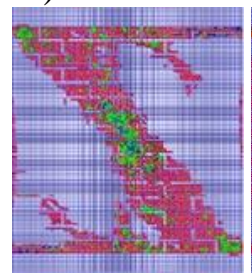

d) JD4-M4

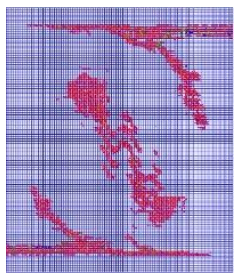

b) JD4-M2

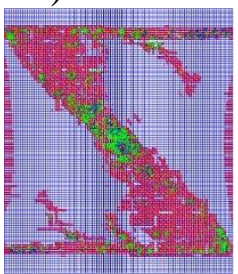

e) JD4-M5

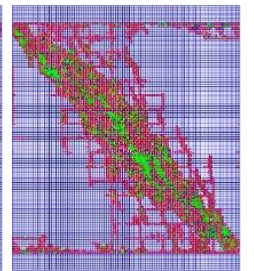

c) JD4-M3

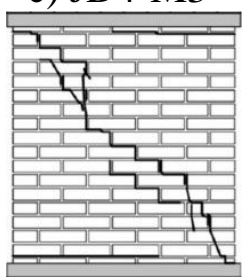

f) Deney
Şekil 5. JD4 Eindhoven duvarının deney ve nümerik çözümlerden elde edilen çatlak bölgeleri.

JD6 duvarının deney sonuçlarından maksimum taban kesme kuvveti $74.87 \mathrm{kN}$ olarak elde edilmiştir. Nümerik analizlerden hesaplanan taban kesme kuvveti değerleri ise JD6-M1, JD6M2, JD6-M3, JD6-M4 ve JD6-M5 için sirasıyla 
$70.78,72.46,71.70,63.49$ ve $90.33 \mathrm{kN}$ olarak elde edilmiştir (Şekil 6).

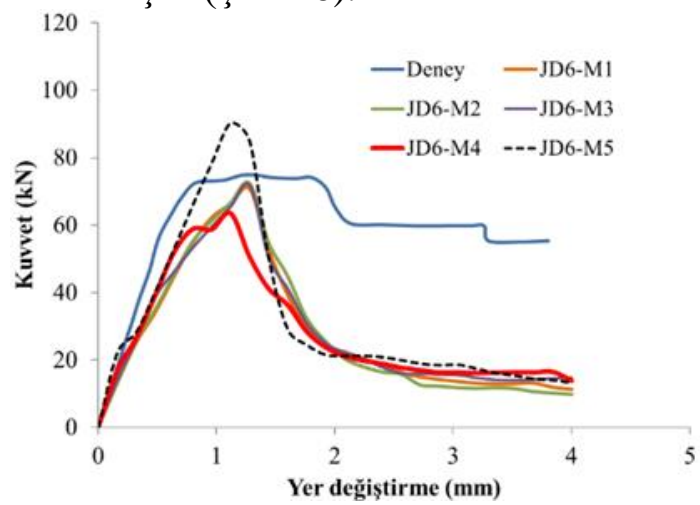

Şekil 6. JD6 Eindhoven duvarının deney ve nümerik çözümlerden elde edilen kuvvet-yer değiştirme grafikleri.

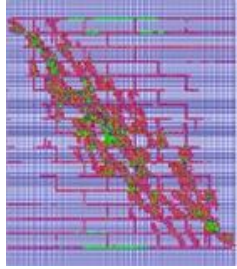

a) JD6-M1

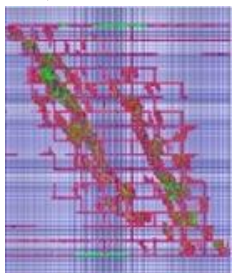

d) JD6-M4

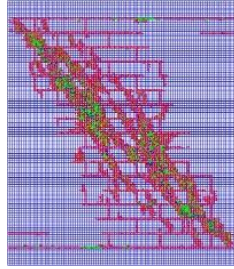

b) JD6-M2

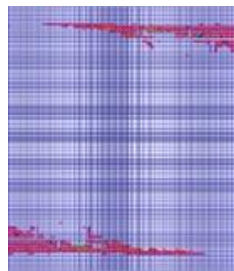

e) JD6-M5

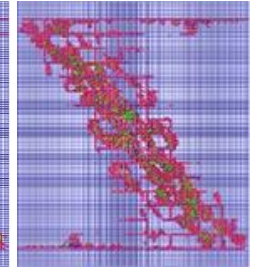

c) JD6-M3

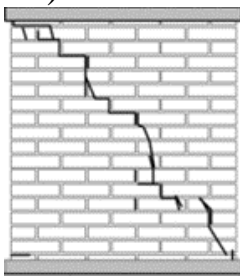

f) Deney
Şekil 7. JD6 Eindhoven duvarinin deney ve nümerik çözümlerden elde edilen çatlak bölgeleri.

Tablo 4. JD6 duvarı için harcın dayanım dĕgeri değişiminin deney ve nümerik sonuçlar arasindaki farklar üzerindeki etkisi.

\begin{tabular}{ccc}
\hline Duvar Adı & $\begin{array}{c}\text { Maks. Taban } \\
\text { Kesme Kuv. } \\
\text { (\% fark) }\end{array}$ & $\begin{array}{c}\text { Eşikyer } \\
\text { değiştirme } \\
\text { (\% fark) }\end{array}$ \\
\hline JD6-M1 & 5.46 & 4.92 \\
JD6-M2 & $\mathbf{3 . 2 2}$ & $\mathbf{4 . 9 2}$ \\
JD6-M3 & 4.24 & 4.92 \\
JD6-M4 & 15.20 & 8.20 \\
JD6-M5 & 20.65 & 8.20 \\
\hline
\end{tabular}

Nümerik sonuçlarda elde edilen maksimum taban kesme kuvveti değerleri deney sonuçlarıyla karşılaştırıldığında; JD6-M1, JD6M2, JD6-M3, JD6-M4 ve JD6-M5 için sirasıyla
$\% 5.46, \% 3.22, \% 4.24, \% 15.20$ ve $\% 20.65$ oranlarında farkların oluştuğu belirlenmiş olup en az fark JD6-M2 için hesaplanmıştır. JD6 duvarının deney sonuçlarından maksimum yükün oluştuğu andaki duvarın tepe yer değiştirme değeri, $1.22 \mathrm{~mm}$ olarak belirlenmiştir. Nümerik analizlerde ise bu yer değiştirme değeri, JD6-M1, JD6-M2, JD6-M3, JD6-M4 ve JD6-M5 için sırasıyla 1.28, 1.28, 1.28, 1.12 ve $1.12 \mathrm{~mm}$ olarak hesaplanmıştır. Deney sonuçlarıyla karşılaştırıldığında bu yer değiştirme değerleri deney sonuçlarına göre sirasiyla $\% 4.92, \% 4.92, \% 4.92, \% 8.20$ ve $\% 8.20$ oranlarında farklar elde edilmiştir. Taban kesme kuvveti ve tepe yer değiştirme değerleri dikkate alındığında her iki büyüklük için en az fark JD6M2 çözümünden elde edilmiştir (Tablo 4).

JD6-M1, JD6-M2, JD6-M3, JD6-M4 ve JD6-M5 için tepe yer değiştirme değerlerinin sirasıyla $1.28,1.28,1.28,1.12$ ve $1.12 \mathrm{~mm}$ ' ye ulaştığ anlarda JD6 duvarında oluşan çatlak bölgeleri ve deneyden elde edilen çatlak bölgeleri Şekil 7' de görülmektedir. Tüm nümerik çözümlerde çatlak bölgeleri JD6 duvarının sağ üst köşesinden başlayıp sola doğru ve sol alt köşesinden başlayıp sağa doğru yatay olarak ilerleyen iki bölge şeklinde elde edilmiştir. İlerleyen yükleme adımlarında JD6-M5 çözümü hariç, sol üst köşeden sağ alt köşeye doğru ilerleyen diyagonel bir çatlak bölgesi daha meydana gelmiştir. JD6M4 çözümünde elde edilen bu diyagonel çatlak bölgesi ise iki parça şeklinde elde edilmiştir.

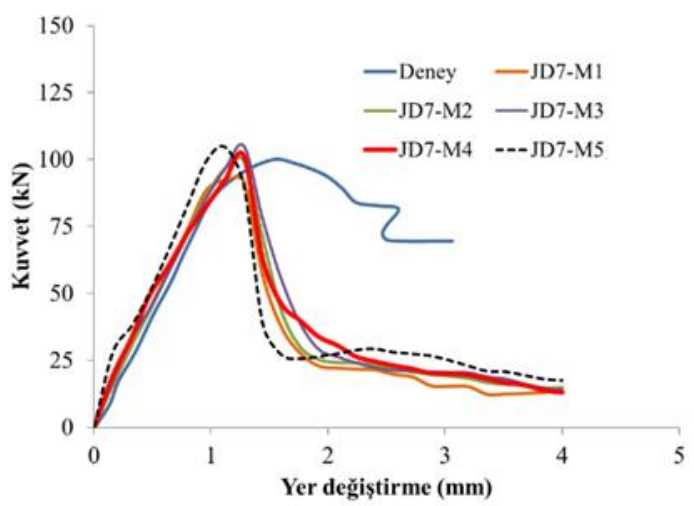

Şekil 8. JD7 Eindhoven duvarının deney ve nümerik çözümlerden elde edilen kuvvet-yer değiştirme grafikleri.

JD7 duvarının deney sonuçlarından maksimum taban kesme kuvveti $100.17 \mathrm{kN}$ olarak 
belirlenmiştir. Nümerik analizlerden hesaplanan taban kesme kuvveti değerleri ise JD7-M1, JD7M2, JD7-M3, JD7-M4 ve JD7-M5 için sırasıyla 93.38, 99.62, 104.98, 101.32 ve $104.70 \mathrm{kN}$ olarak elde edilmiştir (Şekil 8). Hesaplanan maksimum taban kesme kuvveti değerleri deney sonuçlarıyla karşılaştırıldığında; JD7-M1, JD7M2, JD7-M3, JD7-M4 ve JD7-M5 için sırasıyla $\% 7.78, \% 0.55, \% 4.80, \% 1.15$ ve $\% 4.52$ oranlarında farkların oluştuğu belirlenmiştir. $\mathrm{Bu}$ değerler dikkate alındığında en az fark JD7-M2 için hesaplandığı görülmektedir. JD7 duvarının deney sonuçlarından maksimum yükün oluştuğu andaki duvarın tepe yer değiştirme değeri 1.56 $\mathrm{mm}$ olarak belirlenmiştir. Nümerik analizlerde ise bu yer değiştirme değeri, JD7-M1, JD7-M2, JD7-M3, JD7-M4 ve JD7-M5 için sirasiyla 1.12, $1.28,1.28,1.28$ ve $1.12 \mathrm{~mm}$ olarak elde edilmiştir. $\mathrm{Bu}$ yer değiştirme değerleri deney sonucuyla karşılaştırıldığında; deney sonucuna göre sirasiyla $\% 28.20, \% 17.95, \% 17.95, \% 17.95$ ve \%28.20 oranlarında farklar elde edilmiştir. Taban kesme kuvveti ve tepe yer değiştirme değerleri dikkate alındığında her iki büyüklük için en az fark JD7-M2 çözümünden elde edilmiştir (Tablo 5).

JD7-M1, JD7-M2, JD7-M3, JD7-M4 ve JD7-M5 için tepe yer değiştirme değerlerinin sırasıyla $1.12,1.28,1.28,1.28$ ve $1.12 \mathrm{~mm}$ ' ye ulaştığ anlarda JD7 duvarında oluşan çatlak bölgeleri ve deneyden elde edilen çatlak bölgeleri Şekil 9' da görülmektedir.

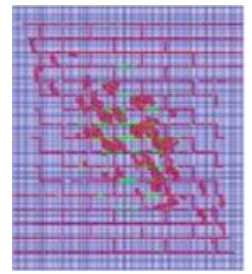

a) JD7-M1

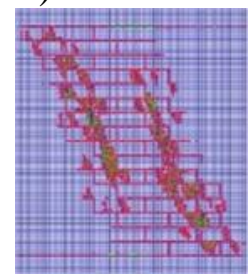

d) JD7-M4

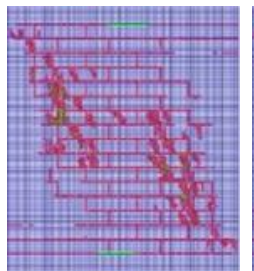

b) JD7-M2

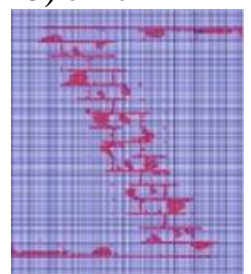

e) JD7-M5

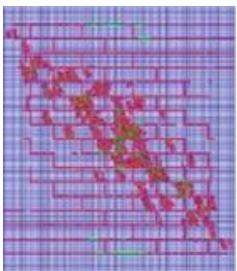

c) JD7-M3

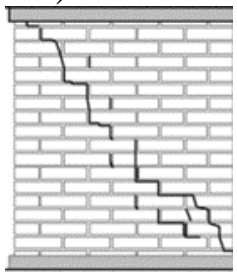

f) Deney
Şekil 9. JD7 Eindhoven duvarınin deney ve nümerik çözümlerden elde edilen çatlak bölgeleri.
Tüm çözümlerde çatlak bölgeleri JD7 duvarının sağ üst köşesinden başlayıp sola doğru ve sol alt köşesinden başlayıp sağa doğru yatay olarak ilerleyen iki bölge şeklinde elde edilmiştir. İlerleyen yükleme adımlarında tüm çözümler için sol üst köşeden sağ alt köşeye doğru ilerleyen diyagonel bir çatlak bölgesi daha meydana gelmiştir. Bu çatlak bölgesi JD7-M5 çözümü haricindeki tüm çözümlerde dağınık bir formda oluşmuştur. Aynı zamanda JD7-M4 çözümünde elde edilen bu diyagonel çatlak bölgesi iki parça şeklinde elde edilmiştir.

Tablo 5. JD7 duvarı için harcın dayanım değeri değişiminin deney ve nümerik sonuçlar arasındaki farklar üzerindeki etkisi.

\begin{tabular}{ccc}
\hline Duvar Adl & $\begin{array}{c}\text { Maks. Taban } \\
\text { Kesme Kuv. } \\
\text { (\% fark) }\end{array}$ & $\begin{array}{c}\text { Eşik yer } \\
\text { değiştirme } \\
\text { (\% fark) }\end{array}$ \\
\hline JD7-M1 & 7.78 & 28.20 \\
JD7-M2 & $\mathbf{0 . 5 5}$ & $\mathbf{1 7 . 9 5}$ \\
JD7-M3 & 4.80 & 17.95 \\
JD7-M4 & 1.15 & 17.95 \\
JD7-M5 & 4.52 & 28.20 \\
\hline
\end{tabular}

$\mathrm{Bu}$ bölümde harcın çekme dayanımı üzerine yapılan nümerik analizler dikkate alındığında, William-Warnke beton modeli için harcın çekme dayanımının 1/20 katsayısı kullanılarak hesaplanabileceği sonucuna ulaşılmıştır.

\section{Harcın $\beta_{t}$ katsayısının çözümler üzerindeki etkisi}

$\mathrm{Bu}$ bölümde JD4, JD6 ve JD7 Eindhoven duvarlarının nümerik çözümlerinde, harç malzemesine ait katsayısının çözümler üzerindeki etkileri incelenmiştir. Harcın kayma gerilmesi iletim katsayıları; çatlağın kapalı durumu için 0.90 seçilmiş olup çatlağın açık durumu için sirasiyla $0.01,0.05,0.1,0.2,0.3$ değerlerinde seçilmiştir. Seçilen bu katsayılara göre adlandirilan duvarlar Tablo 6' da görülmektedir. Tuğlanın kayma gerilmesi iletim katsayıları ise çatlağın açık ve kapalı durumları için sırasıyla 0.05 ve 0.90 olarak alınmıştır. Çözümlerde, tuğla malzemesinin mekanik özellikleri için Tablo 1' de JD4-M2, JD6-M2 ve 
JD7-M2 çözümleri için verilen değerler kullanılmıştır.

Tablo 6. Çatlă̆ın açık durumuna göre isimlendirilen Eindhoven duvarlarl.

\begin{tabular}{cccc}
\hline & $J D 4$ & $J D 6$ & $J D 7$ \\
\hline 0.01 & JD4-MBT1 & JD6-MBT1 & JD7-MBT1 \\
0.05 & JD4-MBT2 & JD6-MBT2 & JD7-MBT2 \\
0.1 & JD4-MBT3 & JD6-MBT3 & JD7-MBT3 \\
0.2 & JD4-MBT4 & JD6-MBT4 & JD7-MBT4 \\
0.3 & JD4-MBT5 & JD4-MBT5 & JD7-MBT5 \\
\hline
\end{tabular}

JD4 duvarının deney sonuçlarından maksimum taban kesme kuvveti $50.30 \mathrm{kN}$ olarak belirlenmiştir. Nümerik analizlerden hesaplanan taban kesme kuvveti değerleri ise JD4-MBT1, JD4-MBT2, JD4-MBT3, JD4-MBT4 ve JD4MBT5 için sırasıyla 37.20, 50.21, 51.85, 51.45 ve $57.00 \mathrm{kN}$ olarak elde edilmiştir (Şekil 10). Hesaplanan maksimum taban kesme kuvveti değerleri deney sonucuyla karşılaştırıldığında; JD4-MBT1， JD4-MBT2， JD4-MBT3， JD4MBT4 ve JD4-MBT5 için sırasıyla \%25.97, $\% 0.13, \% 3.15, \% 2.34$ ve $\% 13.58$ oranlarında farkların oluştuğu belirlenmiştir. $\mathrm{Bu}$ değerler dikkate alındığında en az farkın JD4-MBT2 çözümünden hesaplandığı görülmektedir.

JD4 duvarının deney sonuçlarından maksimum yükün oluştuğu andaki duvarın tepe yer değiştirme değeri $1.74 \mathrm{~mm}$ olarak belirlenmiştir. Nümerik analizlerde ise bu yer değiştirme değeri, JD4-MBT1, JD4-MBT2, JD4-MBT3, JD4-MBT4 ve JD4-MBT5 için sirasıyla 1.28 , $1.60,1.60,1.60$ ve $1.76 \mathrm{~mm}$ olarak elde edilmiştir. $\mathrm{Bu}$ yer değiştirme değerleri deney sonucuyla karşılaştırıldığında sırasıyla \%27.27, $\% 8.05, \% 8.05, \% 8.05$ ve $\% 1.15$ oranlarında farklar elde edilmiştir. $\mathrm{Bu}$ farklar içerisinde en küçük değer JD4-MBT5 çözümünden hesaplanmıştır. Ancak, deney sonuçlarından ve nümerik çözümlerden elde edilen maksimum taban kesme kuvveti değerleri arasındaki farklar dikkate alındığında en büyük farkın bu çözüm için elde edildiği görülmektedir. Bu nedenle en uygun çözümün JD4-MBT2 için olduğu kabul edilmiştir (Tablo 7).
JD4-MBT1， JD4-MBT2， JD4-MBT3， JD4MBT4 ve JD4-MBT5 için tepe yer değiştirme değerlerinin sirasiyla $1.28,1.60,1.60,1.60$ ve $1.76 \mathrm{~mm}$ ' ye ulaştığ 1 anlarda JD4 duvarında oluşan çatlak bölgeleri ve deneyden elde edilen çatlak bölgeleri Şekil 11' de görülmektedir.

Tüm çözümlerde çatlak bölgeleri, JD4 duvarının sağ üst köşesinden başlayıp sola doğru ve sol alt köşesinden başlayıp sağa doğru yatay olarak ilerleyen iki bölge şeklinde elde edilmiştir. İlerleyen yükleme adımlarında sol üst köşeden sağ alt köşeye doğru ilerleyen diyagonel bir çatlak bölgesi daha meydana gelmiştir. Taban kesme kuvveti ve tepe yer değiştirme değerleri için en uygun çözüm olan JD4-MBT2' in hasar bölgesi deneyden elde edilen çatlak yörüngesine benzer bölgelerde meydana gelmiş olup çok dağınık bir formda elde edilmiştir.

Tablo 7. JD4 duvarı için harcın $\beta_{t}$ katsayısı değişiminin deney ve nümerik sonuçlar arasindaki farklar üzerindeki etkisi.

\begin{tabular}{ccc}
\hline Duvar Adl & $\begin{array}{c}\text { Maks. Taban } \\
\text { Kesme Kuv. } \\
\text { (\% fark) }\end{array}$ & $\begin{array}{c}\text { Eşik yer } \\
\text { değiştirme } \\
\text { (\% fark) }\end{array}$ \\
\hline JD4-MBT1 & 25.97 & 27.27 \\
JD4-MBT2 & $\mathbf{0 . 1 3}$ & $\mathbf{8 . 0 5}$ \\
JD4-MBT3 & 3.15 & 8.05 \\
JD4-MBT4 & 2.34 & 8.05 \\
JD4-MBT5 & 13.58 & 1.15 \\
\hline
\end{tabular}

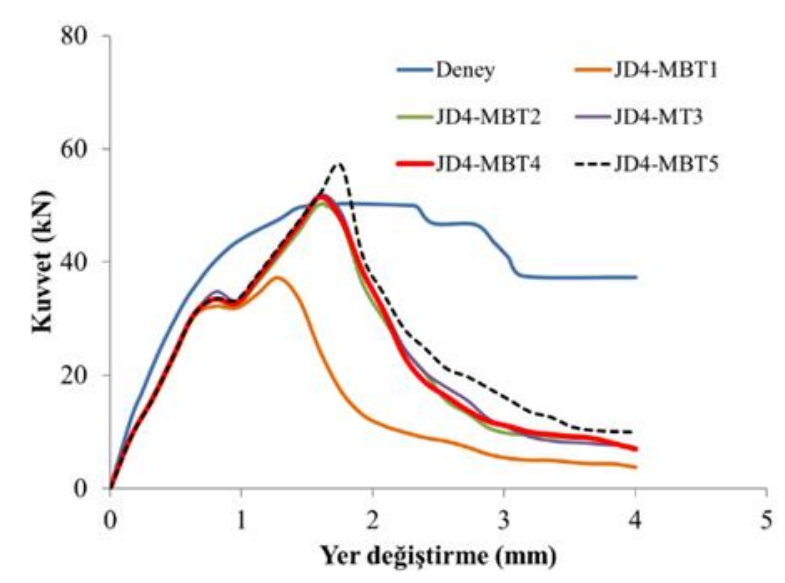

Şekil 10. JD4 Eindhoven duvarının deney ve nümerik çözümlerden elde edilen kuvvet-yer değiştirme grafikleri. 
JD6 duvarının deney sonuçlarından maksimum taban kesme kuvveti $74.87 \mathrm{kN}$ olarak elde edilmiştir. Nümerik analizlerden hesaplanan taban kesme kuvveti değerleri ise JD6-MBT1, JD6-MBT2, JD6-MBT3, JD6-MBT4 ve JD6MBT5 için sırasıyla 71.79, 72.46, 67.67, 73.35 ve $66.94 \mathrm{kN}$ olarak elde edilmiştir (Şekil 12). Hesaplanan maksimum taban kesme kuvveti değerleri deney sonucuyla karşılaştırıldığında; JD6-MBT1，JD6-MBT2， JD6-MBT3， JD6MBT4 ve JD6-MBT5 için sirasıyla \%4.11, $\% 3.22, \% 9.62, \% 2.02$ ve $\% 10.60$ oranlarında farkların oluştuğu belirlenmiş olup en az fark JD6-MBT4 için hesaplanmıştır.
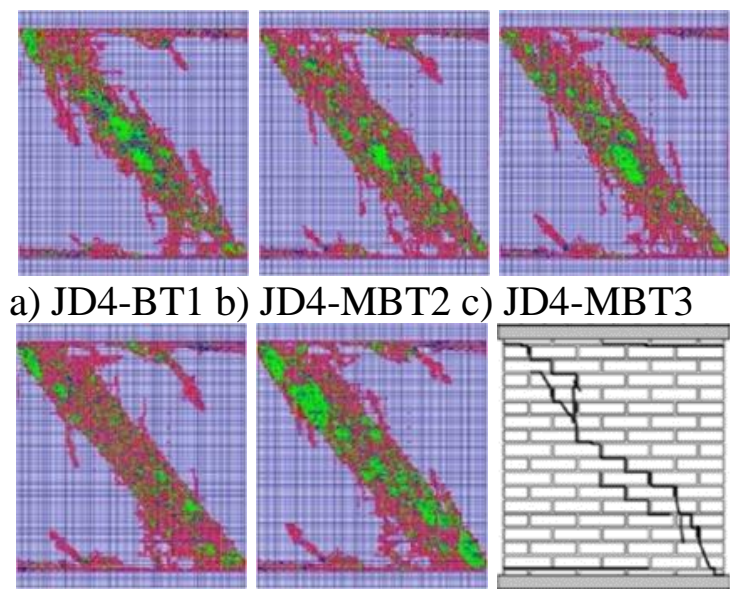

d) JD4-MBT1 e) JD4-MBT5 f) Deney

Şekil 11. JD4 Eindhoven duvarinin deney ve nümerik çözümlerden elde edilen çatlak bölgeleri.

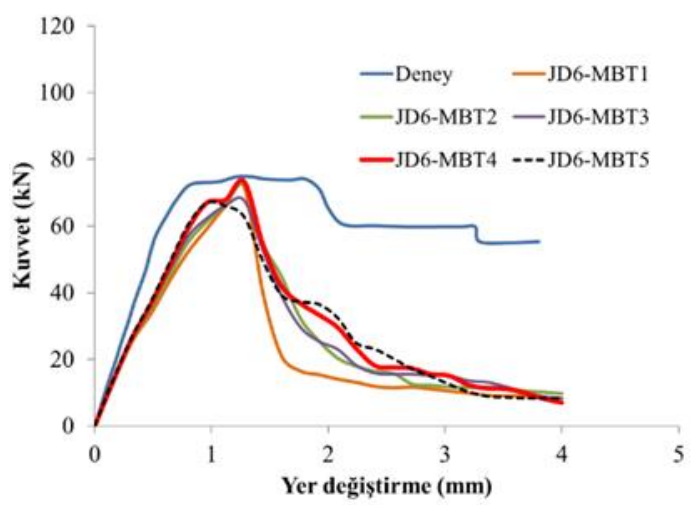

Şekil 12. JD6 Eindhoven duvarinin deney ve nümerik çözümlerden elde edilen kuvvet-yer değiştirme grafikleri.

JD6 duvarının deney sonuçlarından maksimum yükün oluştuğu andaki duvarın tepe yer değiştirme değeri, $1.22 \mathrm{~mm}$ olarak belirlenmiştir. Nümerik analizlerde ise bu yer değiştirme

değeri，JD6-MBT1，JD6-MBT2，JD6-MBT3, JD6-MBT4 ve JD6-MBT5 için sirasiyla 1.28, $1.28,1.28, \quad 1.28$ ve $0.96 \mathrm{~mm}$ olarak hesaplanmıştır. $\mathrm{Bu}$ yer değiştirme değerleri deney sonucuyla karşıllaştırıldığında JD6-MBT1, JD6-MBT2, JD6-MBT3, JD6-MBT4 ve JD6MBT5 çözümleri için sırasıyla \%4.92, \%4.92, $\% 4.92, \% 4.92$ ve $\% 21.31$ oranlarında farkların olduğu belirlenmiştir. Taban kesme kuvveti ve tepe yer değiştirme değerleri dikkate alındığında her iki büyüklük için en az fark, JD6-MBT4 çözümünden elde edilmiştir (Tablo 8).

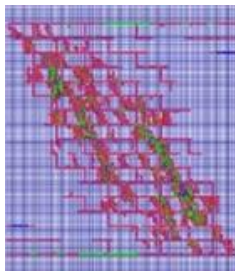

a) JD6-MBT

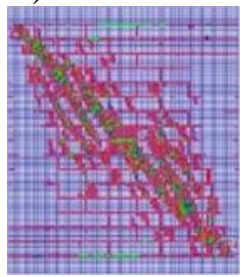

d) JD6-MBT4 e) JD6-MBT5 f) Deney

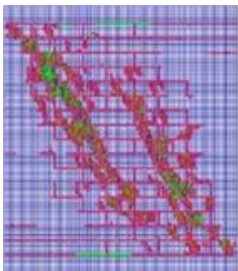

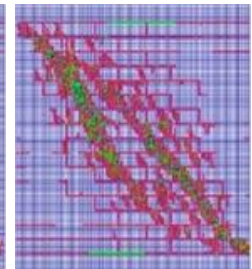

b) JD6-MBT2 c) JD6-MBT3

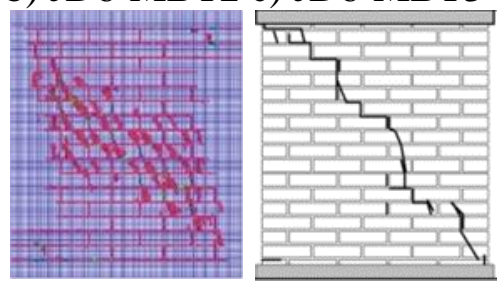

Sekil 13. JD6 Eindhoven duvarının deney ve nümerik çözümlerden elde edilen çatlak bölgeleri.

Tablo 8. JD6 duvarı için harcın $\beta_{t}$ katsayısı değişiminin deney ve nümerik sonuçlar arasındaki farklar üzerindeki etkisi.

\begin{tabular}{ccc}
\hline Duvar Adl & $\begin{array}{c}\text { Maks. Taban } \\
\text { Kesme Kuv. } \\
\text { (\% fark) }\end{array}$ & $\begin{array}{c}\text { Eşik yer } \\
\text { değiştirme } \\
\text { (\% fark) }\end{array}$ \\
\hline JD6-MBT1 & 4.11 & 4.92 \\
JD6-MBT2 & 3.22 & 4.92 \\
JD6-MBT3 & 9.62 & 4.92 \\
JD6-MBT4 & $\mathbf{2 . 0 2}$ & $\mathbf{4 . 9 2}$ \\
JD6-MBT5 & 10.60 & 21.31 \\
\hline
\end{tabular}

JD6-MBT1， JD6-MBT2， JD6-MBT3， JD6MBT4 ve JD6-MBT5 için tepe yer değiştirme değerlerinin sirasiyla $1.28,1.28,1.28,1.28$ ve $0.96 \mathrm{~mm}$ ' ye ulaştı̆̆ 1 anlarda JD6 duvarında oluşan çatlak bölgeleri ve deneyden elde edilen çatlak bölgeleri Şekil 13' de görülmektedir. Tüm 
çözümlerde çatlak bölgeleri JD6 duvarının sağ üst köşesinden başlayıp sola doğru ve sol alt köşesinden başlayıp sağa doğru yatay olarak ilerleyen iki bölge şeklinde elde edilmiştir. İlerleyen yükleme adımlarında, JD6-MBT1, JD6-MBT2 ve JD6-MBT3 çözümlerinden elde edilen bu diyagonel çatlak bölgesi iki parça şeklinde elde edilmiştir. $\quad \mathrm{Bu}$ çatlak bölgesi, JD6-MBT4 ve JD6-MBT5 çözümlerinde ise dağınık bir formda ortaya çıkmıştır.

JD7 duvarının deney sonuçlarından maksimum taban kesme kuvveti $100.17 \mathrm{kN}$ olarak belirlenmiştir. Nümerik analizlerden hesaplanan taban kesme kuvveti değerleri ise JD7-MBT1, JD7-MBT2, JD7-MBT3, JD7-MBT4 ve JD7MBT5 için sırasıyla 94.00, 99.63, 103.81, 107.83 ve $107.76 \mathrm{kN}$ olarak elde edilmiştir (Şekil 14). Hesaplanan maksimum taban kesme kuvveti değerleri deney sonucuyla karşılaştırıldığında; JD7-MBT1， JD7-MBT2, JD7-MBT3, JD7-MBT4 ve JD7-MBT5 için sirasiyla $\% 6.16, \% 0.55, \% 3.63, \% 7.65$ ve $\% 7.58$ oranlarında farkların oluştuğu belirlenmiștir. $\mathrm{Bu}$ değerler dikkate alındığında en az fark, JD7MBT2 için hesaplandığg görülmektedir.

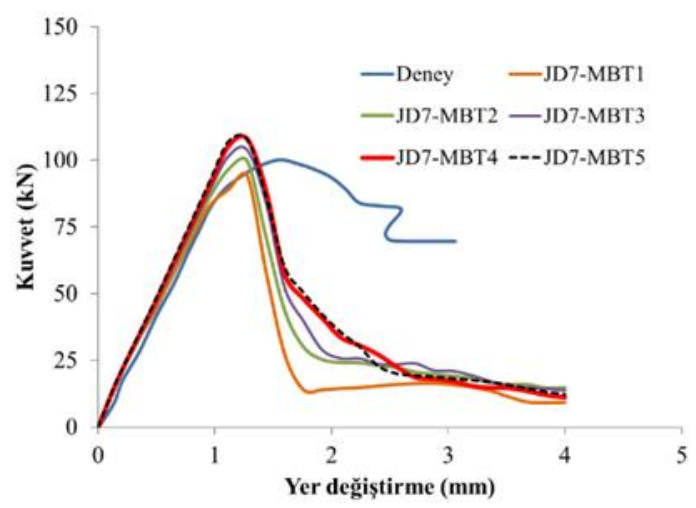

Şekil 14. JD7 Eindhoven duvarının deney ve nümerik çözümlerden elde edilen kuvvet-yer değiştirme grafikleri.

JD7 duvarının deney sonuçlarından maksimum yükün oluştuğu andaki duvarın tepe yer değiştirme değeri $1.56 \mathrm{~mm}$ olarak belirlenmiştir. Nümerik analizlerde ise bu yer değiștirme değeri，JD7-MBT1，JD7-MBT2，JD7-MBT3, JD7-MBT4 ve JD7-MBT5 çözümlerinin tamamında $1.28 \mathrm{~mm}$ olarak hesaplanmıştır. $\mathrm{Bu}$ yer değiştirme değeri deney sonucuyla karşılaştırıldığında \%17.95 oranında daha küçük olarak elde edilmiştir. Taban kesme kuvveti ve tepe yer değiştirme değerleri dikkate alındığında her iki büyüklük için en az fark JD7-MBT2 çözümünden elde edilmiştir (Tablo 9).
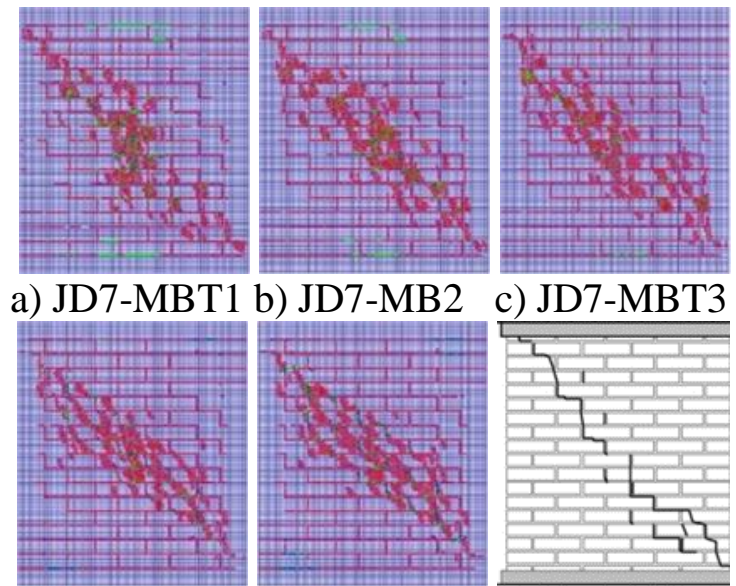

b) JD7-MB2

c) JD7-MBT3
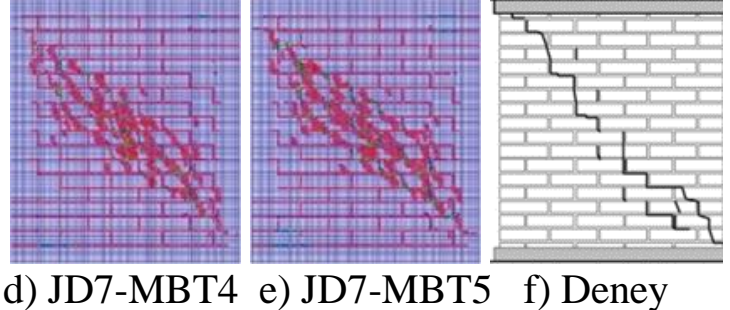

Şekil 15. JD7 Eindhoven duvarinın deneysel ve nümerik çözümlerden elde edilen çatlak bölgeleri.

JD7-MBT1，JD7-MBT2，JD7- MBT3，JD7MBT4 ve JD7-MBT5 için tepe yer değiştirme değerinin $1.28 \mathrm{~mm}$ ' ye ulaştığı anlarda JD7 duvarında oluşan çatlak bölgeleri ve deneyden elde edilen çatlak bölgeleri Şekil 15' de görülmektedir. Tüm çözümlerde çatlak bölgeleri JD7 duvarının sağ üst köșesinden başlayıp sola doğru ve sol alt köşesinden başlayıp sağa doğru ilerleyen iki bölge şeklinde elde edilmiştir. İlerleyen yükleme adımlarında sol üst köședen sağ alt köşeye doğru ilerleyen diyagonel bir çatlak bölgesi daha meydana gelmiştir.

Tablo 9. JD6 duvarı için harcın $\beta_{t}$ katsayısı değişiminin deney ve nümerik sonuçlar arasindaki farklar üzerindeki etkisi.

\begin{tabular}{ccc}
\hline Duvar Adl & $\begin{array}{c}\text { Maks. Taban } \\
\text { Kesme Kuv. } \\
\text { (\% fark) }\end{array}$ & $\begin{array}{c}\text { Eşik yer } \\
\text { değiştirme } \\
\text { (\% fark) }\end{array}$ \\
\hline JD7-MBT1 & 6.16 & 17.95 \\
JD7-MBT2 & $\mathbf{0 . 5 5}$ & $\mathbf{1 7 . 9 5}$ \\
JD7-MBT3 & 3.63 & 17.95 \\
JD7-MBT4 & 7.65 & 17.95 \\
JD7-MBT5 & 7.58 & 17.95 \\
\hline
\end{tabular}




\section{Sonuçlar}

$\mathrm{Bu}$ çalışmada, yı̆̆ma duvarların mikro ölçekli analizinde 3 boyutlu sabit doğrultulu yayılı çatlak modelinin etkinliği incelenmiştir. Nümerik analizler için Ansys sonlu eleman programı içerisinde bulunan Solid65 beton elemanı seçilmiştir. Nümerik sonuçların karşılaştırılması amacıyla, JD4, JD6 ve JD7 Eindhoven duvarlarının deney sonuçlarından elde edilen taban kesme kuvveti-tepe yer değiştirme eğrileri ve oluşan çatlak bölgeleri kullanılmıştır. Sabit doğrultulu yayılı çatlak modelinde, çatlama oluştuktan sonra kayma gerilmelerinin diğer yüzeye iletimi için "kayma gerilmesi transfer katsayısı" tanımlanmaktadır. $\mathrm{Bu}$ çalışmada, harcın çekme dayanımının ve harcin kayma gerilmesi transfer katsayısının çözümler üzerine olan etkisi incelenmiş ve elde edilen sonuçlar aşağıda maddeler halinde verilmiştir;

- Harcin çekme dayanımı üzerine yapılan nümerik analizler dikkate alındığında, WilliamWarnke beton modeli için harcın çekme dayanımının $1 / 20$ katsayısı kullanılarak hesaplanabileceği belirlenmiştir.

- Tüm duvarlarda harcin basinç ve çekme gerilmesi için kayma iletim katsayıları sırasıyla 0.90 ve 0.05 seçildiği zaman deney sonucundan elde edilen taban kesme kuvveti, eşik yer değiștirme değerleri ile nümerik çözümler arasinda sirasiyla en fazla $\% 3.22$ ve $\% 17.95$ ' lik farklar elde edilmiştir.

- Tüm Eindhoven duvarı için ilk hasarlar duvarların sağ üst köşesinden başlayıp sola doğru ve sol alt köşesinden başlayıp sağa doğru yatay olarak ilerleyen iki çatlak bölgesi şeklinde elde edilmiştir. Sonraki yükleme adımlarında ise sol üst köşeden sağ alt köşeye doğru ilerleyen diyagonel bir çatlak bölgesi daha meydana gelmiştir.

\section{Kaynaklar}

[1] Karaton, M., Aksoy, HS., Sayın, E. ve Calayır, Y., "Nonlinear seismic performance of a 12th century historical masonry bridge under different earthquake levels", Engineering Failure Analysis, 79, 408-421. (2017).
[2] Adam, JM., Brencich, A., Hughes, TG. and Jefferson, T., "Micromodelling of eccentrically loaded brickwork: Study of masonry wallettes", Engineering Structures, 32, 1244-1251, (2010).

[3] Mohyeddin, A., Goldsworthy, HM. and Gad, EF., "FE modelling of RC frames with masonry infill panels under in-plane and out-of-plane loading", Engineering Structures, 51, 73-87, (2013).

[4] Petracca, M., Pelà, L., Rossi, R., Zaghi, S., Camata, G. and Spacone, E., "Micro-scale continuous and discrete numerical models for nonlinear analysis of masonry shear walls", Construction and Building Materials, 149, 296-314, (2017).

[5] Zucchini, A., Lourenço, P.B., 2009, A micromechanical homogenisation model for masonry: Application to shear walls, International Journal of Solids and Structures, 46, 871-886.

[6] Vermeltfoort, AT. and Raijmakers, TMJ., "Deformation Controlled Tests in Masonry Shear Walls", Part 2, Eindhoven University of Technology, Netherlands Scientific Report, TUE/BKO/93.08, (1993).

[7] Chaimoon, K., Attard, M. M., 2007. Modeling of unreinforced masonry walls under shear and compression, Engineering Structures, 29, 20562068.

[8] Vermeltfoort, A.Th, Raijmakers T.M.J., Janssen H.J.M., 1993, Shear tests on masonry walls. Proceeding of the 6th North American masonry conference. 1183-93.

[9] DOĞAN, H.N.A, 2016. Yığma duvarların mikro ve makro modelleme teknikleri ile lineer olmayan analizi, YL. Tezi, Frat Üniversitesi Fen Bilimleri Enstitüsü, Elazı ̆̆.

[10] William, KJ. and Warnke, EP., "Constitutive Model for the Tri-axial Behaviour of Concrete, Proceeding of the International Association for Bridge and Structural Engineering", Zurich, Switzerland, 19, 174, (1975).

[11] Zeinkiewicz, OC. and Taylor, RL., "Finite Element Method", McGraw-Hill, Volume 2, 2th Edition, New York, USA, (1991).

[12] Cavicchi, A. and Gambarotta, C., Collapse "Analysis of Masonry Bridges Taking Into Account Arch Fill Interaction”, Engineering Structures, 27, 605-615, (2005).

[13] ANSYS, Finite Element Software, Houston, Texas, USA: Swanson Analysis System. Inc., (2015).

[14] Hemant, BK., Durgesh, CR. and Sudnir, KJ., "Stress-Strain Characteristics of Clay Brick Masonry under Uniaxial Compression", Journal of Materials in Civil Engineering, 19, 728-739, (2007). 